\title{
Anti-nuclear autoantibodies in the general German population: prevalence and lack of association with selected cardiovascular and metabolic disorders - findings of a multicenter population-based study
}

Manas K. Akmatov ${ }^{1,2^{*}+}$, Nadja Röber ${ }^{3+}$, Wolfgang Ahrens ${ }^{4}$, Dieter Flesch-Janys ${ }^{5}$, Julia Fricke ${ }^{6,10}$, Halina Greiser ${ }^{6}$, Kathrin Günther ${ }^{4}$, Rudolf Kaaks ${ }^{6}$, Yvonne Kemmling ${ }^{7}$, Bastian Krone ${ }^{8}$, Jakob Linseisen ${ }^{9}$, Christa Meisinger ${ }^{9}$, Susanne Moebus ${ }^{8}$, Nadia Obi ${ }^{5}$, Carlos A. Guzman ${ }^{11}$, Karsten Conrad ${ }^{3}$ and Frank Pessler ${ }^{1,2}$

\begin{abstract}
Background: We determined the prevalence of anti-nuclear autoantibodies (ANAs) in the German adult population and examined the association between ANAs and cardiovascular and metabolic disorders.

Methods: We used data and blood samples from the pretest phases of the German National Cohort, obtained from six of the 18 study centers $(n=1199)$. All centers applied standardized instruments including face-to-face interviews, anthropometric measurements and collection of blood samples. Self-reported histories of diabetes mellitus, heart attack and elevated blood cholesterol and/or lipids were recorded. Height, weight and blood pressure were measured. ANAs were detected using a semi-automated system (AKLIDES ${ }^{\oplus}$; Medipan $\mathrm{GmbH}$, Dahlewitz, Germany). A positive ANA was defined as a titer $\geq 1: 80$. ANA were classified as weakly (1:80 or 1:160), moderately (1:320 or 1:640) or strongly ( $\geq 1: 1280)$ positive. Specific autoantibodies against nuclear antigens were detected with second-step assays according to the ANA staining pattern. Associations between the assessed disorders and ANA positivity and pattern were examined using sex and age-adjusted mixed-effects logistic regression models.
\end{abstract}

Results: Thirty-three percent (95\% confidence interval; 31-36\%) of the 1196 participants (measurements could not be obtained from three samples) were ANA positive (titer $\geq 1: 80$ ). The proportions of weakly, moderately and strongly positive ANA were 29\%, 3.3\% and 1.3\%, respectively. ANA positivity was more common among women than men across all titers $\left(X^{2}, p=0.03\right)$. ANA positivity, even when stratified according to height of titer or immunofluorescent pattern, was not associated with diabetes, elevated blood cholesterol and/or lipids, obesity or hypertension. Second-step autoantibody assays were positive in 41 of the 83 samples (49\%) tested, with anti-DFS70 $(n=13)$ and anti-dsDNA $(n=7)$ being most frequent. These subgroups were too small to test for associations with the disorders assessed.

(Continued on next page)

\footnotetext{
*Correspondence: manas.akmatov@twincore.de

'Equal contributors

${ }^{1}$ TWINCORE, Centre for Experimental and Clinical Infection Research,

Feodor-Lynen-Straße 7, 30625 Hannover, Germany

${ }^{2}$ Helmholtz Centre for Infection Research, Braunschweig, Germany

Full list of author information is available at the end of the article
} 
(Continued from previous page)

Conclusions: The prevalence of ANA positivity in the German general population was similar to values reported from other countries. Contrary to other studies, there was no association with selected self-reported and objectively measured cardiovascular and metabolic variables.

Keywords: Anti-nuclear autoantibodies, Diabetes, German National Cohort, Hypertension, Metabolism, Obesity, Population-based study

\section{Background}

Anti-nuclear autoantibodies (ANAs) are immunoglobulins commonly used as an initial test to screen for connective tissue diseases such as systemic lupus erythematosus (SLE), systemic sclerosis, polymyositis, dermatomyositis or Sjögren's syndrome $(\mathrm{SjS})$ [1]. The ANA diagnostic is a sensitive test to evaluate these diseases, particularly SLE. However, the presence of ANAs is not specific for any particular connective tissue disease and can be associated with various other conditions such as cancer, chronic infections and cardiovascular diseases, and with use of certain medications [2,3]. Even all-cause mortality has been associated with a positive ANA test [4]. One possible explanation for this phenomenon is that the presence of ANAs may reflect an increased baseline level of general inflammation and/or autoimmunity that is deleterious to the function of more than one organ. Tests for ANAs can also be positive in healthy individuals, particularly in low titers. For instance, a population-based study in China reported that approximately $6 \%$ of healthy individuals tested positive for ANA with a titer of 1:320 [5]. In a Mexican study, ANAs were detected in 35\% of healthy individuals (titer 1:40) [6]. A higher risk of ANA positivity is associated with female sex [7] and increasing age [5]. Evidence is emerging that associations may also exist between ANA positivity and certain parameters of cardiovascular and metabolic dysfunction. For instance, high ANA titers have been associated with coronary atherosclerosis [8], and individuals positive for ANA were reported to be more likely to develop myocardial infarction and peripheral vascular disease [9]. In terms of metabolic endpoints, Gonzalez et al. [10] found an inverse association between obesity and ANA positivity in women (but none in men), and Heras et al. [11] observed higher ANA positivity among individuals with type 1 diabetes than among nondiabetic individuals. To our knowledge, there are no data derived from the German general population on ANA prevalence or the association between ANA positivity and cardiovascular and metabolic disorders. The aims of the present study were therefore to determine the prevalence of ANAs in a multicenter population-based study in Germany and to examine their association with selected cardiovascular and metabolic disorders.

\section{Methods \\ Sampling}

The German National Cohort (GNC, in German also known as the NaKo Gesundheitsstudie) is a large-scale multicenter population-based prospective cohort study aiming to recruit 200,000 male and female participants between 20 and 69 years of age in 18 study centers distributed across Germany [12]. Recruitment of participants for the main study started in 2014. For the present study, we used data and blood samples from the first and second pretest studies of the GNC conducted in 2011 and 2012, respectively, and covering six study centers (Augsburg, Bremen, Essen, Hamburg, Hannover and Heidelberg). The aim of the pretest studies was to test the feasibility of selected instruments. Population-based sampling was used to recruit participants, and therefore samples were drawn from population registries of the respective municipalities. In addition, in two study centers (Essen and Heidelberg), selected migrant populations were recruited using register and community-based approaches [13]. The latter included recruitment via social networks (e.g., in groceries frequented by migrants, mosques or general practitioners' offices). The study population in Essen comprised individuals of Turkish origin only; in Heidelberg, in addition to nonmigrant individuals, recruitment included the two largest migrant population groups-that is, individuals of Turkish origin and ethnic German immigrants from the former Soviet Union (FSU resettlers) [13]. In both study centers, bilingual study documents (e.g., flyers, posters, questionnaires, etc.) were offered.

The proportion of older individuals was oversampled in that $26.7 \%$ were recruited in each of the three older age groups (40-49, 50-59 and 60-69 years) and 10\% in each of the younger age groups (20-29 and 30-39 years). Individuals were contacted through land mail; nonresponders received up to two reminders and up to 10 telephone calls (provided that telephone numbers could be identified). Computer-assisted face-to-face interviews were performed to collect sociodemographic and health-related data in all study centers except Essen, where a questionnaire was administered. Anthropometric measurements were obtained from all participants. Finally, biologic specimens (e.g., blood, urine and stool samples, nasal swabs) were collected. 


\section{Outcome variables}

As part of the medical history, information on chronic diseases and medical events relevant to the presented study was collected by the questions "Have you ever been diagnosed with ... [diabetes mellitus, myocardial infarction, elevated blood cholesterol and/or lipids] by a physician?", with separate "yes", "no" and "I don't know" options for each item. Height and body weight were measured with the SECA 285 measuring station (SECA, Hamburg, Germany). Body mass index (BMI) was calculated using the formula weight $/$ height ${ }^{2}\left(\mathrm{~kg} / \mathrm{m}^{2}\right)$. BMI $\geq 25 \mathrm{~kg} / \mathrm{m}^{2}$ and $\mathrm{BMI} \geq 30 \mathrm{~kg} /$ $\mathrm{m}^{2}$ were used to define overweight and obesity, respectively [14]. Blood pressure was measured three times within a 15-minute period with an HEM 705 IT blood pressure monitor (OMRON Healthcare Europe, the Netherlands), except in Essen where it was measured only once. We calculated the mean of the second and third measurements and defined hypertension as a systolic or diastolic blood pressure higher than $140 \mathrm{mmHg}$ and/or $90 \mathrm{mmHg}$, respectively [15]. The study center in Essen was excluded from this analysis because only a single measurement was available. Self-reported information on hypertension was not used in our analysis.

\section{ANA as exposure variable}

First, we divided the participants into two groups; negative and positive for ANA. A titer of at least 1:80 was used to define positivity. Second, participants were divided into four ANA subgroups: negative, weakly positive (titer 1:80 or $1: 160$ ), moderately positive (titer $1: 320$ or $1: 640$ ) and strongly positive (titer $\geq 1: 1280$ ).

\section{Laboratory analyses}

ANAs were detected by indirect immunofluorescence on HEp- 2 cells. The assessment of autoantibody titers and five main patterns (granular/fine granular, homogeneous/ homogeneous fine granular, nucleolar, centromer and other patterns) was carried out with a semi-automated system (AKLIDES ${ }^{\circ}$ Medipan GmbH, Dahlewitz, Germany) [1618 ] and confirmed by visual observation. Sera assessed as positive (titer $\geq 1: 80$ ) were further analyzed by specific second-step autoantibody assays according to the staining pattern. The selection of the following confirmatory assays was carried out according to test algorithms of routine diagnostics. For sera with granular/fine granular pattern, antibodies against Ro/SS-A, La/SS-B, U1-RNP and Sm were determined by ELISAs (Orgentec Diagnostika GmbH, Germany). Furthermore, immunodiffusion with extractable nuclear antigen (Hiss diagnostics $\mathrm{GmbH}$, Germany) was applied. If homogeneous or homogeneous fine granular pattern occurred, ELISAs for the detection of antibodies against dsDNA, histones and nucleosomes (Seramun diagnostica GmbH, Germany) and Bioflash ${ }^{\circ}$ chemiluminescence assay for the determination of DFS-70 antibodies (INOVA diagnostics Inc., USA) were performed. If a nucleolar pattern was observed, the EUROLINE $^{\bullet}$ Immunoblot (EUROIMMUN Medizinische Labordiagnostika AG, Germany) for the detection of PMScl and Scl-70 antibodies was carried out. Because anticentromere antibodies provide a specific pattern on HEp-2cells, no antigen-specific confirmatory assay was necessary.

\section{Statistical analysis}

Initially, we performed a descriptive analysis by study center. The differences in sociodemographic variables across the study centers were examined with the chi-square test or Fisher's exact test. Furthermore, we pooled the data from all study centers and estimated the sex and agespecific prevalence of ANAs. The differences in ANA positivity between sex and country of birth were tested with the chi-square test or Fisher's exact test. As a next step, we applied mixed-effects logistic regression analysis to examine the association between ANA positivity and cardiovascular and metabolic disorders. The models were adjusted for sex and age; the study center was included as a random effect. The procedure PROC GLIMMIX was used for mixed-effects logistic regression analysis. For this analysis, moderately and strongly positive samples were combined into one category because the proportion of strongly positive samples was very low to be analyzed separately. The analysis was performed with the statistical program SAS for Windows, version 9.2 (SAS Institute Inc., Cary, NC, USA) and R Foundation for Statistical Computing software (version 3.0.2).

\section{Results}

\section{Description of the study population}

Table 1 presents selected demographic and clinical data and ANA positivity by study center and for the total study population. The proportion of women was higher in all study centers, with the greatest differences in Essen and Heidelberg. The proportion of obese participants was twice as high in Essen as in the other study centers. There were apparent, albeit not statistically significant, differences across centers in the proportions of self-reported heart attacks (Fisher's exact test, $p=0.18$ ) or diabetes $\left(\chi^{2}=5.129\right.$, $\mathrm{df}=5, p=0.40$; Fisher's exact test, $p=0.19$ ).

\section{Sex and age-specific ANA prevalence rates}

The proportion of participants with a positive ANA test (titer $\geq 1: 80$ ) was $33.3 \%$ (95\% confidence intervals: 30.7 $35.9 \%)$. There was a trend toward more frequent ANA positivity with increasing age among women $\left(x^{2}=6.983\right.$, $\mathrm{df}=4, p$ for trend $=0.09$ ) but not men. With the exception of the age group 30-39, the proportion of ANA positivity was higher among women than men in all age groups, with the most significant difference in the age group 50-59 (Fig. 1). There was no significant difference 
Table 1 Sociodemographic characteristics, morbidities and ANA distributions of the study groups (\%)

\begin{tabular}{|c|c|c|c|c|c|c|c|c|}
\hline & $\begin{array}{l}\text { Augsburg } \\
(n=139)\end{array}$ & $\begin{array}{l}\text { Bremen } \\
(n=241)\end{array}$ & $\begin{array}{l}\text { Essen } \\
(n=282)\end{array}$ & $\begin{array}{l}\text { Hamburg } \\
(n=238)\end{array}$ & $\begin{array}{l}\text { Hannover } \\
(n=106)\end{array}$ & $\begin{array}{l}\text { Heidelberg } \\
(n=193)\end{array}$ & $p$ value ${ }^{a}$ & $\begin{array}{l}\text { Total } \\
(n=1199)\end{array}$ \\
\hline Sex & & & & & & & 0.168 & \\
\hline Male & 48.2 & 45.2 & 39.1 & 47.9 & 47.2 & 38.9 & & 43.8 \\
\hline Female & 51.8 & 54.8 & 60.9 & 52.1 & 52.8 & 61.1 & & 56.2 \\
\hline Median age (IQR) & $55(47-63)$ & $54(41-62)$ & $41(34-50)$ & $48(30-62)$ & $52(43-62)$ & $45(31-59)$ & $<0.0001^{\mathrm{b}}$ & $49(38-60)$ \\
\hline Country of birth & & & & & & & $<0.0001$ & \\
\hline Germany & 83.5 & 83.8 & 21.3 & 88.7 & 87.7 & 40.9 & & 64.0 \\
\hline Other & 16.5 & 16.3 & 78.7 & 11.3 & 12.3 & 59.1 & & 36.0 \\
\hline BMl & & & & & & & $<0.0001$ & \\
\hline Underweight $\left(<18.50 \mathrm{~kg} / \mathrm{m}^{2}\right)$ & 0 & 1.2 & 0.4 & 1.7 & 2.8 & 2.6 & & 1.3 \\
\hline Normal weight (18.50-24.99 kg/m²) & 33.8 & 43.2 & 18.5 & 51.1 & 46.2 & 46.9 & & 38.7 \\
\hline Overweight (25.00-29.99 kg/m²) & 46.8 & 39.0 & 39.9 & 32.5 & 35.8 & 31.3 & & 37.3 \\
\hline Obesity $\left(\geq 30.00 \mathrm{~kg} / \mathrm{m}^{2}\right)$ & 19.4 & 16.6 & 41.3 & 14.8 & 15.1 & 19.3 & & 22.7 \\
\hline Heart attack & & & & & & & 0.18 & \\
\hline Yes & 5.0 & 0.8 & 2.3 & 1.7 & 2.8 & 2.6 & & 2.3 \\
\hline No & 95.0 & 99.2 & 97.7 & 98.3 & 97.2 & 97.4 & & 97.7 \\
\hline Diabetes & & & & & & & 0.40 & \\
\hline Yes & 7.2 & 5.4 & 9.9 & 5.9 & 4.7 & 6.8 & & 6.8 \\
\hline No & 92.8 & 94.6 & 90.1 & 94.1 & 95.3 & 93.2 & & 93.2 \\
\hline ANA positivity & & & & & & & 0.742 & \\
\hline Negative $(<1: 80)$ & 67.6 & 63.9 & 66.8 & 65.1 & 71.7 & 68.8 & & 66.7 \\
\hline Positive ( $\geq 1: 80)$ & 32.4 & 36.1 & 33.2 & 34.9 & 28.3 & 31.3 & & 33.3 \\
\hline ANA positivity & & & & & & & 0.157 & \\
\hline Negative $(<1: 80)$ & 67.6 & 63.9 & 66.8 & 65.1 & 71.7 & 68.8 & & 66.7 \\
\hline Weakly positive (1:80 \& 1:160) & 25.2 & 29.0 & 29.6 & 32.4 & 26.4 & 25.5 & & 28.6 \\
\hline Moderately positive (1:320 \& 1:640) & 3.6 & 5.8 & 2.5 & 1.3 & 1.9 & 4.7 & & 3.3 \\
\hline Strongly positive ( $\geq 1: 1280)$ & 3.6 & 1.2 & 1.1 & 1.3 & 0 & 1.0 & & 1.3 \\
\hline
\end{tabular}

ANA anti-nuclear autoantibody, IQR interquartile range, $B M I$ body mass index

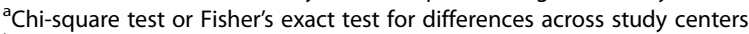

${ }^{\mathrm{b}}$ Kruskal-Wallis test for differences across study centers

in the proportion of positive samples across study centers (Table $1, \mathrm{X}^{2}=2.727, \mathrm{df}=5, p=0.742$ ). Of the 1196 participants with available ANA results (measurements could not be obtained from three samples), 342 (28.6\%), $40(3.3 \%)$ and $16(1.3 \%)$ were classified as weakly, moderately and strongly positive, respectively. The prevalence of weakly, moderately and strongly positive ANA titers was higher among women than men (Fig. $2 \mathrm{a}, \mathrm{X}^{2}=8.859$, $\mathrm{df}=3, p=0.03)$. There were no differences in ANA positivity between participants born in Germany and abroad (Fig. 2b).

\section{ANA staining patterns}

The most frequent ANA staining patterns were granular/ fine granular pattern (74.1\%), followed by homogeneous/ homogeneous fine granular (19.2\%) and nucleolar (2.6\%) (Fig. 3a). The granular/fine granular pattern predominated in samples with weak ANA positivity (Fig. 3b). The centromere pattern was only present among strongly ANA-positive samples (Fig. 3b).

\section{Second-step autoantibody detection}

The results of confirmatory testing for 19 specific autoantibodies are presented in Table 2. Of the 10 (53\%) detected autoantibodies, anti-DFS70 $(n=13)$ and anti-dsDNA $(n=7)$ were the most frequently detected. There was a tendency for more frequent positivity for secondstep autoantibodies with increasing ANA titer $\left(x^{2}=\right.$ 3.072, $\mathrm{df}=1, n=83, p$ for trend $=0.08$ ). 


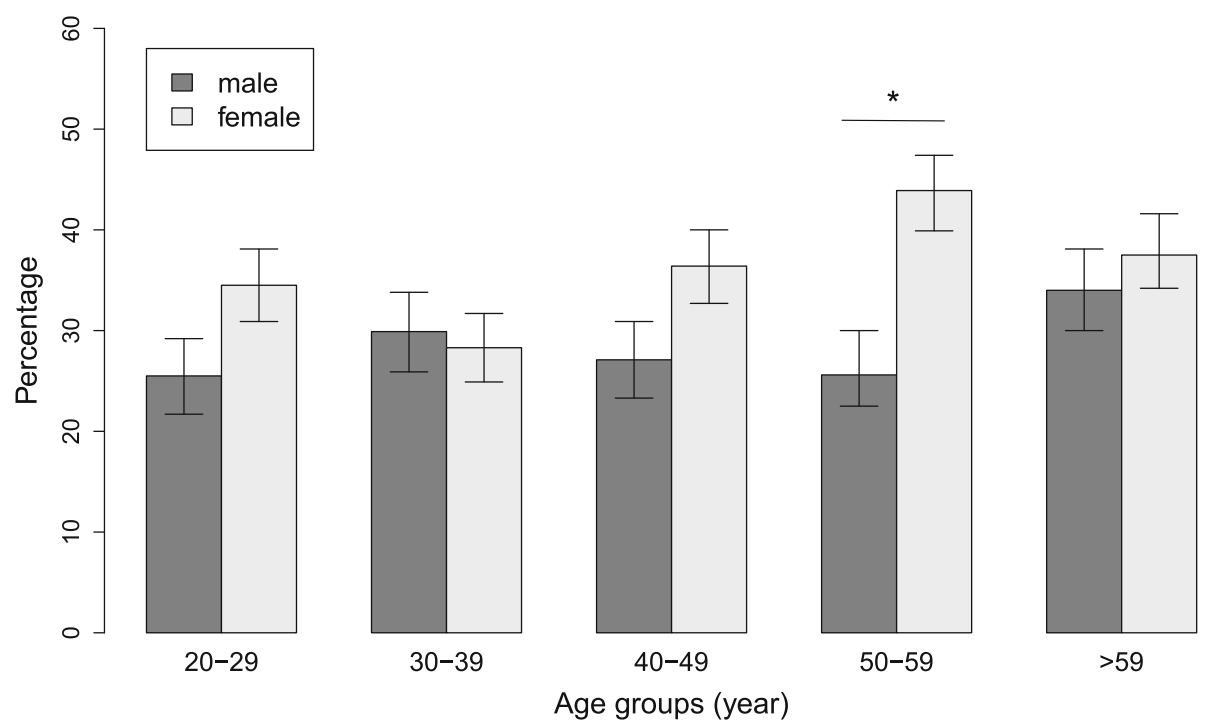

Fig. 1 ANA positivity by sex and age groups. ANA positivity was defined as a titer $\geq 1: 80$. Whiskers indicate $95 \%$ confidence intervals. ${ }^{*} p=0.003$

\section{Association between ANA and cardiovascular and metabolic disorders}

Table 3 presents age and sex-adjusted ORs for the cardiovascular and metabolic parameters assessed. There was no association between ANA positivity and the selfreported (diabetes, elevated blood cholesterol/lipids) or objectively measured (obesity, hypertension) parameters. Likewise, there were no associations between ANA staining patterns and these variables, even when only individuals with titers $\geq 1: 80$ were considered (data not shown). An association with heart attack could not be tested due to the low number of reported cases (Table 1).

\section{Discussion}

Using a semi-automated high-throughput system, we determined the frequencies of ANAs in the German general population at different titer cutoff point and patterns and looked for associations with selected cardiovascular and metabolism-related diseases. The detected prevalences were comparable with published values from
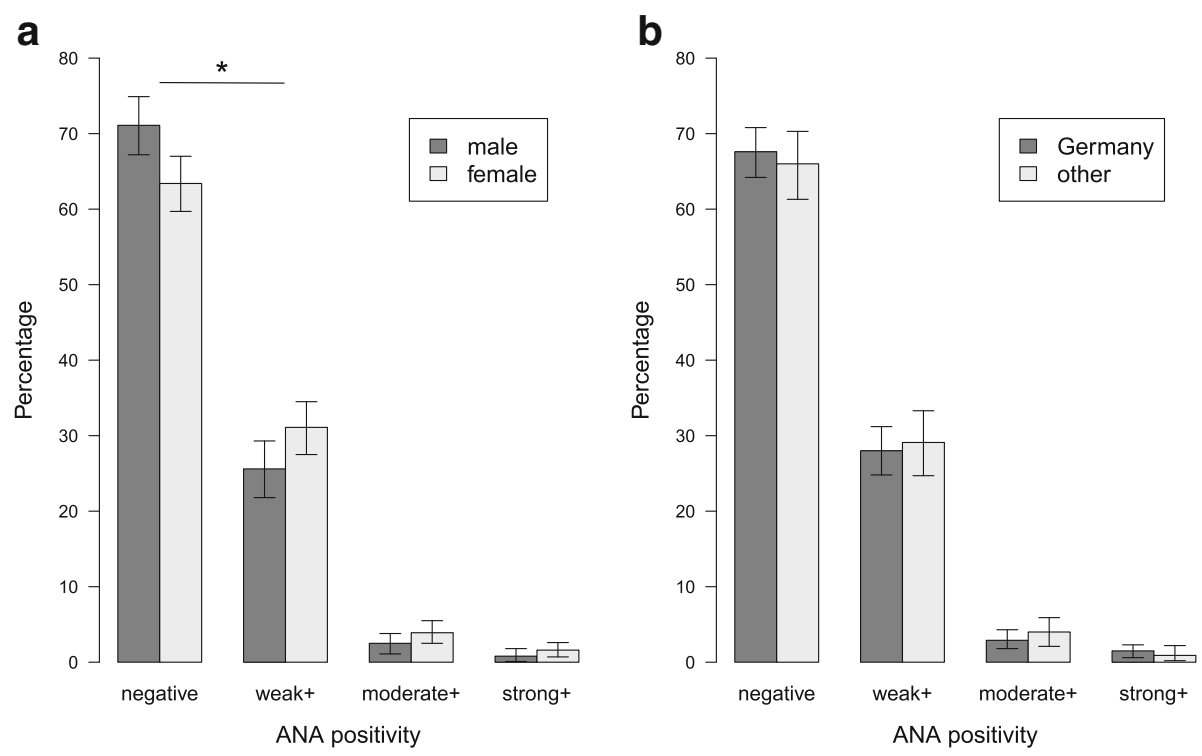

Fig. 2 Proportion of weakly, moderately and strongly positive ANA titers by sex (a) and by country of birth (b) (weak, 1:80 or 1:160; moderate, $1: 320$ or 1:640; strong, $\geq 1: 1280)$. Difference in ANA positivity by sex was significant $\left(x^{2}=8.859, \mathrm{df}=3, p=0.03\right)$. ${ }^{*} p=0.02$. Difference in ANA positivity by country of birth was not significant $\left(x^{2}=1.121, d f=3, p=0.77\right)$. Whiskers indicate $95 \%$ confidence intervals. ANA anti-nuclear autoantibody 

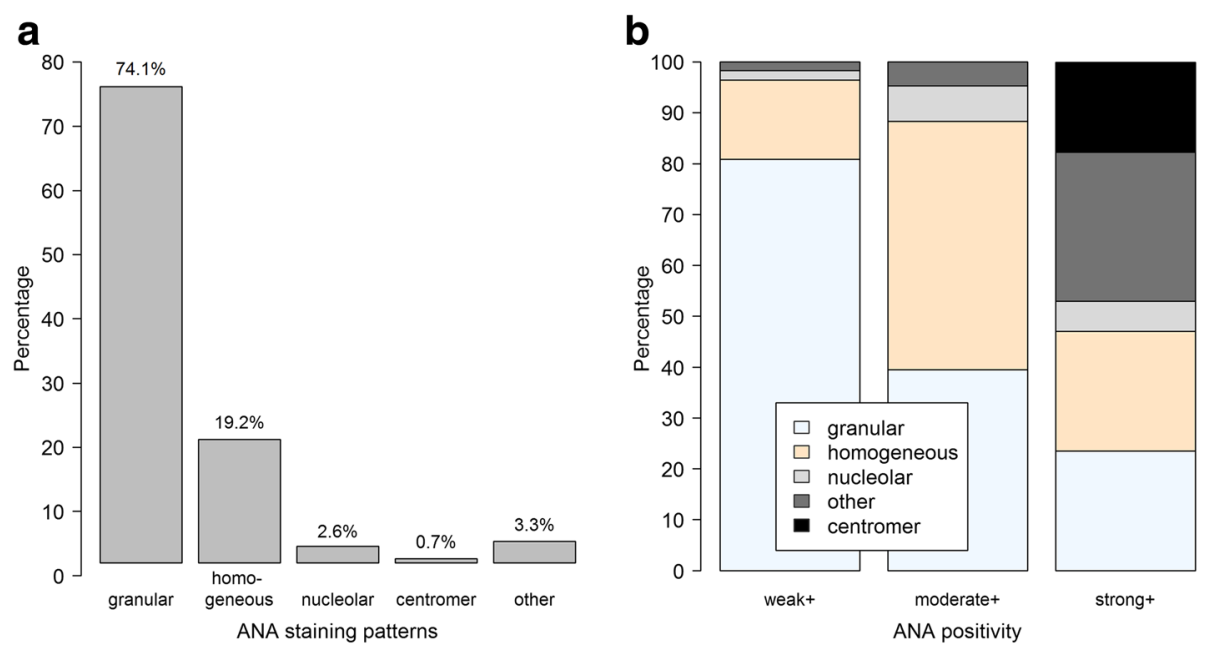

Fig. 3 ANA staining patterns. Frequencies of patterns across all samples (a) and according to degree of positivity (b) (weak, 1:80 or 1:160; moderate, 1:320 or 1:640; strong, $\geq 1: 1280$ ). ANA anti-nuclear autoantibody

other studies, but we did not detect any associations between ANAs at any titer or pattern and the cardiovascular and metabolic diseases assessed.

Only a few studies on ANA prevalence have so far been conducted among the general population $[5,6,19]$. None of them used population-based sampling as we did. A Mexican study involving healthy individuals (blood donors, health care workers and relatives of patients with connective tissue disorders) demonstrated similar prevalence rates; for example, an ANA positivity of $35 \%$ with a titer $\geq 1: 40$ [6]. Guo et al. [5] used a titer cutoff point of 1:320 to determine ANA positivity among

Table 2 Proportion of positive results for specific auto-antibodies from confirmatory assays (\%)

\begin{tabular}{|c|c|c|c|c|c|}
\hline \multirow[b]{2}{*}{ Antibody } & \multirow[b]{2}{*}{ Number of positive results ( $n$ ) } & \multirow[b]{2}{*}{ Proportion of positive results for all antibodies $(\%)(N=83)$} & \multicolumn{3}{|c|}{$\begin{array}{l}\text { Number and proportion of positive results } \\
\text { in samples with ANA titer }(n(\%))\end{array}$} \\
\hline & & & $1: 80$ and $1: 160$ & $1: 320$ and $1: 640$ & $\geq 1: 1280$ \\
\hline DFS-70 & 13 & 15.7 & $3(23)$ & $6(46)$ & $4(31)$ \\
\hline dsDNA & 7 & 8.4 & $2(29)$ & $5(71)$ & $0(0)$ \\
\hline SSA & 4 & 4.8 & $0(0)$ & $2(50)$ & $2(50)$ \\
\hline Nukl & 4 & 4.8 & $1(25)$ & $3(75)$ & $0(0)$ \\
\hline Histon & 4 & 4.8 & $0(0)$ & $4(100)$ & $0(0)$ \\
\hline AMA & 2 & 2.4 & $0(0)$ & $0(0)$ & $2(100)$ \\
\hline CENPB & 2 & 2.4 & $0(0)$ & $0(0)$ & $2(100)$ \\
\hline ENA & 2 & 2.4 & $0(0)$ & $2(100)$ & $0(0)$ \\
\hline sp100 & 2 & 2.4 & $0(0)$ & $0(0)$ & $2(100)$ \\
\hline SSB & 1 & 1.2 & $0(0)$ & $1(100)$ & $0(0)$ \\
\hline Myositis blot & 0 & 0 & $0(0)$ & $0(0)$ & $0(0)$ \\
\hline SSC blot & 0 & 0 & $0(0)$ & $0(0)$ & $0(0)$ \\
\hline Rib-P & 0 & 0 & $0(0)$ & $0(0)$ & $0(0)$ \\
\hline Jo-1 & 0 & 0 & $0(0)$ & $0(0)$ & $0(0)$ \\
\hline U1 RNP & 0 & 0 & $0(0)$ & $0(0)$ & $0(0)$ \\
\hline $\mathrm{Sm}$ & 0 & 0 & $0(0)$ & $0(0)$ & $0(0)$ \\
\hline Gp210 & 0 & 0 & $0(0)$ & $0(0)$ & $0(0)$ \\
\hline LBR & 0 & 0 & $0(0)$ & $0(0)$ & $0(0)$ \\
\hline F-actin & 0 & 0 & $0(0)$ & $0(0)$ & $0(0)$ \\
\hline
\end{tabular}


Table 3 Age and sex-adjusted odds ratios for the cardiovascular and metabolic disorders assessed (results of the four mixed-effects logistic regression models)

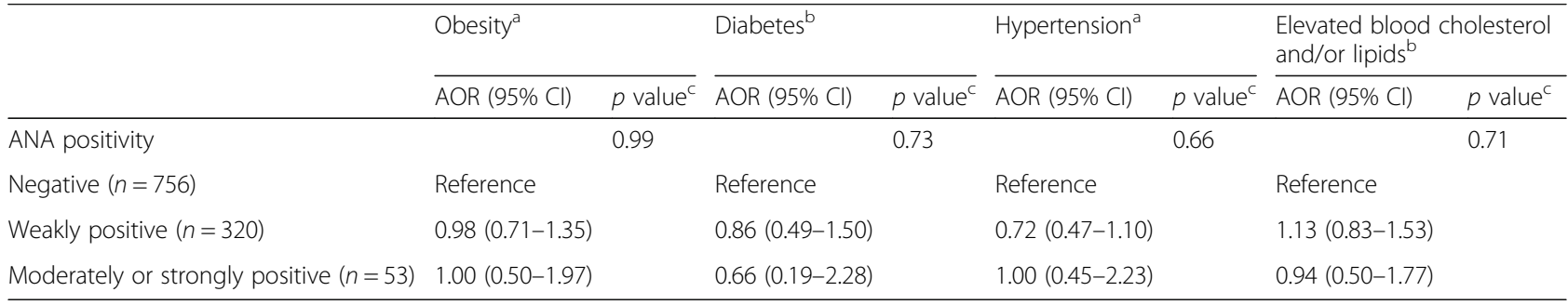

ANA anti-nuclear autoantibody, $A O R$ adjusted odds ratio, $B M I$ body mass index, $C l$ confidence interval

${ }^{a}$ Objectively measured weight and height and blood pressure (see Methods). Obesity was defined as BMI $\geq 30 \mathrm{~kg} / \mathrm{m}^{2}$. Hypertension was defined as a systolic or diastolic blood pressure $\geq 140 \mathrm{mmHg}$ and/or $90 \mathrm{mmHg}$, respectively

${ }^{b}$ Self-reported information

'Tests of fixed effects

healthy individuals in China and showed that around 6\% of participants were positive. This figure was comparable with our study. Andersen-Ranberg et al. [20] examined the prevalence of nonorgan-specific autoantibodies among Danish healthy centenarians and observed a slightly higher ANA prevalence $(37 \%$, titer $\geq 1: 40)$ than in our study. The international recommendation for the determination of ANA indicates titers of 1:160 or above as positive [21], and the European Autoimmunity Standardization Initiative (EASI) recommends sera with titers of $1: 80$ as borderline and with titers $\geq 1: 160$ to be considered positive [22]. The aim of both initiatives was to improve the diagnostics of patients with systemic autoimmune rheumatic diseases, but not the examination of the prevalence of ANA in the general population. Therefore, as suggested by the manufacturer of the HEp-2-cell assay, in our study we used a titer $\geq 1: 80$ to define sera as positive. This cutoff point represents a sensitivity of $98.1 \%$ and a specificity of $91.2 \%$ of the AKLIDES system for the detection of ANAs in 156 sera with defined antinuclear antibodies and 263 nonselected blood donors [23]. Low ANA titers may not be of clinical significance [1], but higher titers might predict the development of autoimmune diseases such as SLE. Arbuckle et al. [24] investigated the onset of ANAs before diagnosis of SLE and observed that ANAs (with a dilution of $1: 120$ ) were present in $78 \%$ of SLE patients before diagnosis. We found about $3.3 \%$ and $1.3 \%$ of our participants to have moderately (titer of $1: 320$ or 1:640) and

Table 4 Summary of publications reporting associations between ANAs and various cardiovascular and metabolic disorders and death

\begin{tabular}{|c|c|c|c|c|c|c|c|}
\hline $\begin{array}{l}\text { Author/ } \\
\text { year }\end{array}$ & Country & $\begin{array}{l}\text { Study } \\
\text { design }\end{array}$ & Sample size & $\begin{array}{l}\text { Participants' age, } \\
\text { mean } \pm \text { SD }\end{array}$ & Outcome & $\begin{array}{l}\text { Method used to } \\
\text { measure the } \\
\text { outcome }\end{array}$ & Main findings \\
\hline $\begin{array}{l}\text { Sedaghat } \\
\text { et al. } 2014 \\
\text { [3] }\end{array}$ & Iran & $\begin{array}{l}\text { Patient- } \\
\text { based }\end{array}$ & 140 & $56.4 \pm 10.8$ & $\begin{array}{l}\text { Ischemic heart disease, } \\
\text { comparison of ANA positivity } \\
\text { between patients with acute } \\
\text { coronary syndrome and } \\
\text { chronic stable angina }\end{array}$ & $\begin{array}{l}\text { Coronary } \\
\text { angiography }\end{array}$ & $\begin{array}{l}\text { ANA positivity higher in } \\
\text { patients with chronic stable } \\
\text { angina; association with } \\
\text { severity of coronary stenotic } \\
\text { lesions }\end{array}$ \\
\hline $\begin{array}{l}\text { Chou et al. } \\
2011[4]\end{array}$ & China & $\begin{array}{l}\text { Patient- } \\
\text { based }\end{array}$ & 13,345 & $11.4 \pm 5.0$ & Risk of death & $\begin{array}{l}\text { National Death } \\
\text { Registry }\end{array}$ & $\begin{array}{l}\text { High titer of ANAs associated } \\
\text { with increased risk of death }\end{array}$ \\
\hline $\begin{array}{l}\text { Heras et al. } \\
2010[11]\end{array}$ & Greece & $\begin{array}{l}\text { Patient- } \\
\text { based }\end{array}$ & $\begin{array}{l}70 \text { (type } 1 \\
\text { diabetes) } 28 \\
\text { (type } 2 \text { diabetes) } \\
20 \text { (control) }\end{array}$ & $\begin{array}{l}34.0 \pm 9.164 .0 \\
\pm 9.545 .0 \pm \\
16.2\end{array}$ & Diabetes & Not mentioned & $\begin{array}{l}\text { ANA positivity higher in } \\
\text { type } 1 \text { diabetes than in } \\
\text { healthy individuals }\end{array}$ \\
\hline $\begin{array}{l}\text { Gonzalez } \\
\text { et al. } 2008 \\
{[10]}\end{array}$ & $\begin{array}{l}\text { Canary } \\
\text { Islands }\end{array}$ & $\begin{array}{l}\text { Community- } \\
\text { based }\end{array}$ & 702 & Not reported & Obesity & $\begin{array}{l}\text { Anthropometric } \\
\text { measurements (BMI, } \\
\text { waist circumference, } \\
\text { waist/height ratio) }\end{array}$ & $\begin{array}{l}\text { Inverse association with } \\
\text { obesity in women, no } \\
\text { association in men }\end{array}$ \\
\hline $\begin{array}{l}\text { Ishikawa } \\
\text { et al. } 2008 \\
\text { [25] }\end{array}$ & Japan & $\begin{array}{l}\text { Community- } \\
\text { based }\end{array}$ & 2875 & $63.0 \pm 10.0$ & $\begin{array}{l}\text { Microalbuminuria, BMI, } \\
\text { diabetes, hypertension, } \\
\text { hypercholesterolemia }\end{array}$ & $\begin{array}{l}\text { Almost all outcomes } \\
\text { measured }\end{array}$ & $\begin{array}{l}\text { Bivariate analysis: no } \\
\text { association between BMI, } \\
\text { diabetes, hypertension and } \\
\text { ANA positivity }\end{array}$ \\
\hline $\begin{array}{l}\text { Liang et al. } \\
2009[9]\end{array}$ & USA & $\begin{array}{l}\text { Patient- } \\
\text { based }\end{array}$ & 7852 & $47.5 \pm 17.0$ & $\begin{array}{l}\text { Myocardial infarction, heart } \\
\text { failure, peripheral vascular } \\
\text { disease and risk of death }\end{array}$ & Medical records & $\begin{array}{l}\text { ANAs associated with } \\
\text { increased risk of } \\
\text { cardiovascular diseases and } \\
\text { mortality }\end{array}$ \\
\hline
\end{tabular}


strongly $(\geq 1: 1280)$ positive titers, respectively. These individuals may be at higher risk of developing autoimmune diseases.

Why did our study not detect any association between ANA titer and/or pattern and the selected cardiovascular and metabolic variables? One reason may lie in the inherent methodological differences from other studies on the topic (summarized in Table 4). In contrast to those studies, which used diagnoses from medical records and were based on physical examinations, our analysis was based in part on participants' self-reported information regarding diabetes and elevated blood cholesterol (see Methods). However, the lack of associations between ANAs and BMI or hypertension was determined based on physical measurements obtained in the study centers. This finding agrees with the lack of association with hypertension reported by Ishikawa et al. [25], but also suggests that the association with BMI in women reported by Gonzalez et al. [10] may not apply across populations.

We used the AKLIDES semi-automated system because it would lend itself well to high-throughput ANA determinations of large sample numbers typical of present-day "mega cohorts" like the GNC. Hospital-based studies showed that the AKLIDES system yields comparable results to the gold standard (i.e., visual inspection and evaluation by a clinical immunologist). For instance, Bizzaro et al. [26] found that the diagnostic accuracy of the AKLIDES system for automated ANA assessment was very high (sensitivity, 97.8\%). Melegari et al. [27] observed very high agreement (98.9\%) between automated and visual assessments of the AKLIDES system. Our study now demonstrated the feasibility of also using the AKLIDES system in a population-based analysis. Taken together, the results support the use of this system in future large-scale population-based studies that require the high-throughput capability of this system.

Limitations of the present study include its crosssectional nature, which precludes causal inferences. Because the overall sample size was relatively small, it may not have been sufficient to detect significant associations between ANA positivity and the metabolic outcome variables studied. Thus, further research examining these relationships is required. It would have been important to validate the clinical relevance of ANA positivity, in particular of high titer, by testing for associations with autoimmune disorders such as SLE or SjS. However, this was not possible due to the very low numbers of selfreported cases $(\mathrm{SLE}=4 ; \mathrm{SjS}=7)$, which are consistent with the low prevalences of these disorders in Germany $[28,29]$. We pooled data from two cross-sectional studies (i.e. pretests 1 and 2), which were conducted in 2011 and 2012. There were slight differences in the designs of the questionnaires used in the pretest 1 and 2 studies and in the methodology of the studies. For example, blood pressure was only measured once in the Essen study center, while it was measured three times in the other study centers. In terms of metabolic disorders the questions did not differ. Further supporting our use of the pooled data set, there were no differences in ANA positivity between samples from pretest 1 vs. pretest 2 .

\section{Conclusions}

The prevalence of ANA positivity in the German general population was similar to values reported from other countries. Contrary to other studies, there was no association between ANA positivity and self-reported and objectively measured selected cardiovascular and metabolic disorders.

\section{Abbreviations}

ANA: Anti-nuclear autoantibody; BMI: Body mass index; FSU: Former Soviet Union; GNC: German National Cohort; SjS: Sjögren's syndrome; SLE: Systemic lupus erythematosus

\section{Acknowledgements}

The authors thank the participants and the study center staff for making this study possible, Uta Kießling and Christine Gräfe for expert assistance with ANA measurements in Dresden, and Thomas Illig (Hannover Medical School, Hannover, Germany) for a critical reading of the manuscript and helpful discussion.

\section{Funding}

The field study was conducted in the context of the pretest studies of the GNC (www.nako.de). These were funded by the Federal Ministry of

Education and Research (BMBF, grant no. 01ER1001A-I) and supported by the Helmholtz Association as well as by the participating universities and Institutes of the Leibniz Association. The study was also supported by the Helmholtz Association's Portfolio Topic "Metabolic Dysfunction and Chronic Disease" and by iMed_-the Helmholtz Association's Initiative on Personalized Medicine.

\section{Availability of data and materials}

The dataset used in the study is available from the corresponding author.

\section{Authors' contributions}

MKA participated in planning the study, analyzed the data and wrote the first draft of the manuscript. NR participated in ANA measurements and data analysis, and edited the manuscript. YK, JL, CM, WA, KG, SM, BK, NO, DF-J, JF, $\mathrm{HG}$ and RK recruited study participants, collected biosamples and helped to revise the manuscript. CAG participated in writing the manuscript. KC participated in planning the study, oversaw the ANA measurements and participated in writing the manuscript. FP conceived and oversaw the study, participated in writing the manuscript, had access to all data and takes responsibility for their integrity. All authors read and approved the final manuscript.

\section{Competing interests}

The authors declare that they have no competing interests.

\section{Consent for publication \\ Not applicable.}

\section{Ethics approval and consent to participate}

All studies on humans described in the present manuscript were carried out with the approval of the responsible ethics committee (Augsburg: Ethics Committee of the State Board of Physicians of the German federal state of Bavaria; Bremen: Ethics Committee of the University of Bremen; Essen: Ethics Committee of the University Clinics of Essen; Hannover: Ethics Committee of the State Board of Physicians of the German federal state of Lower Saxony; Hamburg: Ethics Committee of the State Board of Physicians of the federal state of Hamburg; and Heidelberg: Ethics Committee of the Medical Faculty of Heidelberg). Informed consent was obtained from all participants. 


\section{Publisher's Note}

Springer Nature remains neutral with regard to jurisdictional claims in published maps and institutional affiliations.

\section{Author details \\ ${ }^{1}$ TWINCORE, Centre for Experimental and Clinical Infection Research, Feodor-Lynen-Straße 7, 30625 Hannover, Germany. ${ }^{2}$ Helmholtz Centre for Infection Research, Braunschweig, Germany. ${ }^{3}$ Institute of Immunology, Technical University Dresden, Dresden, Germany. ${ }^{4}$ Leibniz Institute for Prevention Research and Epidemiology-BIPS, Bremen, Germany. ${ }^{5}$ University Medical Center Hamburg-Eppendorf, Hamburg, Germany. ${ }^{6}$ German Cancer Research Center (DKFZ), Heidelberg, Germany. ${ }^{7}$ Department of Epidemiology, Helmholtz Centre for Infection Research, Braunschweig, Germany. ${ }^{8}$ Institute for Medical Informatics, Biometry and Epidemiology (IMIBE), University Clinics of Essen, Essen, Germany. ${ }^{9}$ Helmholtz Zentrum München, Institute for Epidemiology II, Neuherberg, Germany. ${ }^{10}$ Institute for Social Medicine, Epidemiology and Health Economics, Charité-Universitätsmedizin Berlin, Berlin, Germany. ${ }^{11}$ Department of Vaccinology and Applied Microbiology, Helmholtz Centre for Infection Research, Braunschweig, Germany.}

Received: 13 May 2016 Accepted: 18 May 2017

Published online: 06 June 2017

\section{References}

1. O'Sullivan M, McLean-Tooke A, Loh RK. Antinuclear antibody test. Aust Fam Physician. 2013;42:718-21.

2. Volkmann ER, Taylor M, Ben-Artzi A. Using the antinuclear antibody test to diagnose rheumatic diseases: when does a positive test warrant further investigation? South Med J. 2012;105:100-4.

3. Sedaghat A, Sadeghi M, Heidari R, Sistani E, Bayanfar Z. Rheumatoid factor, anti-nuclear antibody in ischemic heart disease: acute versus chronic patients. ARYA Atheroscler. 2014;10:305-10.

4. Chou IJ, Kuo CF, See LC, Hsia SH, Yu KH, Luo SF, Wu CT, Huang JL. Antinuclear antibody status and risk of death in children and adolescents. Scand J Rheumatol. 2011;40:472-7.

5. Guo YP, Wang CG, Liu X, Huang YQ, Guo DL, Jing XZ, Yuan CG, Yang $S$, Liu JM, Han MS, Li HX. The prevalence of antinuclear antibodies in the general population of china: a cross-sectional study. Curr Ther Res Clin Exp. 2014;76:116-9.

6. Marin GG, Cardiel MH, Cornejo H, Viveros ME. Prevalence of antinuclear antibodies in 3 groups of healthy individuals: blood donors, hospital personnel, and relatives of patients with autoimmune diseases. J Clin Rheumatol. 2009;15:325-9.

7. Li Q, Karp D, Quan J, Branch V, Zhou J, Lian Y, Chong B, Wakeland E, Olsen N. Risk factors for ANA positivity in healthy persons. Arthritis Res Ther. 2011;13:R38.

8. Grainger DJ, Bethell HW. High titres of serum antinuclear antibodies, mostly directed against nucleolar antigens, are associated with the presence of coronary atherosclerosis. Ann Rheum Dis. 2002;61:110-4.

9. Liang KP, Kremers HM, Crowson CS, Snyder MR, Therneau TM, Roger VL, Gabriel SE. Autoantibodies and the risk of cardiovascular events. J Rheumatol. 2009:36:2462-9.

10. Gonzalez DA, De Leon AC, Rodriguez Perez MC, Coello SD, Gonzalez HA, Fuentes RC, Jaime AA, Diaz BB. Inverse association between obesity and antinuclear antibodies in women. J Rheumatol. 2008;35:2449-51.

11. Heras P, Mantzioros M, Mendrinos D, Heras V, Hatzopoulos A, Xourafas V, Kritikos K, Karagiannis S. Autoantibodies in type 1 diabetes. Diabetes Res Clin Pract. 2010;90:e40-2.

12. GNC Consortium. The German National Cohort: aims, study design and organization. Eur J Epidemiol. 2014;29:371-82.

13. Reiss K, Dragano N, Ellert U, Fricke J, Greiser KH, Keil T, Krist L, Moebus S, Pundt N, Schlaud M, Yesil-Jurgens R, Zeeb H, Zimmermann H, Razum O, Jockel $\mathrm{KH}$, Becher $\mathrm{H}$. Comparing sampling strategies to recruit migrants for an epidemiological study. Results from a German feasibility study. Eur J Public Health. 2014;24:721-6.

14. World Health Organization. Global database on Body Mass Index - an interactive surveillance tool for monitoring nutrition transition. http://apps. who.int/bmi/index.jsp. Accessed 16 Jul 2015.

15. Chobanian AV, Bakris GL, Black HR, Cushman WC, Green LA, Izzo Jr JL, Jones DW, Materson BJ, Oparil S, Wright Jr JT, Roccella EJ. Seventh report of the
Joint National Committee on Prevention, Detection, Evaluation, and Treatment of High Blood Pressure. Hypertension. 2003;42:1206-52.

16. Knutter I, Hiemann R, Brumma T, Buttner T, Grossmann K, Cusini M, Pregnolato F, Borghi MO, Anderer U, Conrad K, Reinhold D, Roggenbuck D, Csernok E. Automated interpretation of ANCA patterns-a new approach in the serology of ANCA-associated vasculitis. Arthritis Res Ther. 2012;14:R271.

17. Egerer K, Roggenbuck D, Hiemann R, Weyer MG, Buttner T, Radau B, Krause R, Lehmann B, Feist E, Burmester GR. Automated evaluation of autoantibodies on human epithelial-2 cells as an approach to standardize cell-based immunofluorescence tests. Arthritis Res Ther. 2010;12:R40.

18. Meroni PL, Bizzaro N, Cavazzana I, Borghi MO, Tincani A. Automated tests of ANA immunofluorescence as throughput autoantibody detection technology: strengths and limitations. BMC Med. 2014;12:38.

19. Serrano-Osuna R, Lopez-Lopez RM, Brito-Zurita OR, Sabag-Ruiz E, PerezFernandez $\mathrm{H}$, Ornelas-Aguirre JM. Seroprevalence of antinuclear antibodies in blood donors in the Yaqui Valley. Cir Cir. 2014;82:619-27.

20. Andersen-Ranberg K, Hoier-Madsen M, Wiik A, Jeune B, Hegedus L. High prevalence of autoantibodies among Danish centenarians. Clin Exp Immunol. 2004;138:158-63.

21. Agmon-Levin N, Damoiseaux J, Kallenberg C, Sack U, Witte T, Herold M, Bossuyt X, Musset L, Cervera R, Plaza-Lopez A, Dias C, Sousa MJ, Radice A, Eriksson C, Hultgren O, Viander M, Khamashta M, Regenass S, Andrade LE, Wiik A, Tincani A, Ronnelid J, Bloch DB, Fritzler MJ, Chan EK, Garcia-De La Torre I, Konstantinov KN, Lahita R, Wilson M, Vainio O, Fabien N, Sinico RA, Meroni P, Shoenfeld $Y$. International recommendations for the assessment of autoantibodies to cellular antigens referred to as anti-nuclear antibodies. Ann Rheum Dis. 2014;73:17-23.

22. Sack U, Conrad K, Csernok E, Frank I, Hiepe F, Krieger T, Kromminga A, von Landenberg P, Messer G, Witte T, Mierau R. Autoantibody detection using indirect immunofluorescence on HEp-2 cells. Ann N Y Acad Sci. 2009;1173:166-73

23. Hiemann R, Buttner T, Krieger T, Roggenbuck D, Sack U, Conrad K. Challenges of automated screening and differentiation of non-organ specific autoantibodies on HEp-2 cells. Autoimmun Rev. 2009;9:17-22.

24. Arbuckle MR, McClain MT, Rubertone MV, Scofield RH, Dennis GJ, James JA, Harley JB. Development of autoantibodies before the clinical onset of systemic lupus erythematosus. N Engl J Med. 2003;349:1526-33.

25. Ishikawa M, Konta T, Hao Z, Takasaki S, Abiko H, Takahashi T, Ikeda A, Ichikawa K, Shibata Y, Takeishi Y, Kato T, Kawata S, Kubota I. Relationship between antinuclear antibody and microalbuminuria in the general population: the Takahata study. Clin Exp Nephrol. 2008;12:200-6.

26. Bizzaro N, Antico A, Platzgummer S, Tonutti E, Bassetti D, Pesente F, Tozzoli $\mathrm{R}$, Tampoia M, Villalta D. Automated antinuclear immunofluorescence antibody screening: a comparative study of six computer-aided diagnostic systems. Autoimmun Rev. 2014;13:292-8.

27. Melegari A, Bonaguti C, Russo A, Luisita B, Trenti T, Lippi G. A comparative study on the reliability of an automated system for the evaluation of cell-based indirect immunofluorescence. Autoimmun Rev. 2012;11:713-6.

28. Brinks R, Fischer-Betz R, Sander O, Richter JG, Chehab G, Schneider M. Age-specific prevalence of diagnosed systemic lupus erythematosus in Germany 2002 and projection to 2030. Lupus. 2014;23:1407-11.

29. Gaubitz M. Epidemiology of connective tissue disorders. Rheumatology (Oxford). 2006;45 Suppl 3:iii3-4

\section{Submit your next manuscript to BioMed Central and we will help you at every step:}

- We accept pre-submission inquiries

- Our selector tool helps you to find the most relevant journal

- We provide round the clock customer support

- Convenient online submission

- Thorough peer review

- Inclusion in PubMed and all major indexing services

- Maximum visibility for your research

Submit your manuscript at www.biomedcentral.com/submit
) Biomed Central 